\title{
Using Iron-Chelating Agents in Critically Ill Patients with Iron Overload. Fact or Fiction?
}

\author{
Hadi Darvishi-Khezri
}

Thalassemia Research Center (TRC), Hemoglobinopathy Institute, Mazandaran University of Medical Sciences, Sari, Iran

\begin{tabular}{|c|c|}
\hline Article Info & Corresponding Information: \\
\hline \multirow[t]{2}{*}{ doi $10.30699 /$ jambs.29.133.123 } & Hadi Darvishi-Khezri, Thalassemia Research Center (TRC), Hemoglobinopathy \\
\hline & Received: 2020/02/04; Accepted: 2020/10/14; Published Online: 04 Dec 2020 \\
\hline $\begin{array}{l}\text { Copyright } \odot 2021 \text {, This is an } \\
\text { copy and redistribution of the }\end{array}$ & $\begin{array}{l}\text { 1-access article distributed under the terms of the Creative Commons Attribution-noncommercial } 4.0 \text { International License which permits } \\
t \text { in noncommercial usages with proper citation. }\end{array}$ \\
\hline
\end{tabular}

\section{Dear Editor in Chief}

Recently, some evidence has shown that the failure of iron homeostasis may occur in critically ill patients and can lead to iron overload $(1,2)$. Elevated ferritin levels as a body iron burden index in critically ill patients may be associated with depressed level of consciousness and greater mortality $(3,4)$. However, the necessity of using iron-chelating agents in clinical situation is still unknown for these cases.

Oxidative stress, inflammation and increased iron stores are concepts related to each other. Oxidative stress has been defined by an imbalance between pro-oxidant and antioxidant conditions, which along with boosted inflammatory response have been commonly reported in critical situation in patients admitted to the intensive care unit (ICU) $(5,6)$. Inflammation and oxidative stress can also be considered as one of the most important probable causes of increased iron stores in critical patients (7). Likewise, iron excess promotes the generation of reactive oxygen species (ROS) and oxidative stress via "Fenton reaction", as well as the increase of susceptibility to infection (2). It should be mentioned that the relationship between iron overload and infectious diseases has been relatively proved (7). Imbalance iron metabolism and iron overload status can be deteriorated after emerging infection in these patients.

Some studies have clued that the higher level of ferritin is correlated with lethal outcome and mortality in ill ICU cases $(1,4)$. Tacke et al., (1) compared serum iron indices in 1,020 patients with sepsis, 43 non-septic cases and 156 healthy blood donors. The results showed that the levels of serum ferritin and hepcidin — as a key regulator of the entry of iron into the circulation - were significantly increased among ICU cases as compared with healthy subjects. The levels of serum ferritin and hepcidin were remarkably greater in septic patients. The rise of hepcidin levels as an alteration of iron homeostasis in critically ill cases may ensue from increased serum ferritin subsequent to inflammation and possibly an infectious (7).
In conclusion, iron overload may happen in a specific time in critical patients during ICU admission, which can be diagnosed to launch an appropriate treatment for regulation of iron balance (8). Theoretically, iron homeostasis can be preserved through checking the serum levels of ferritin, total iron binding capacity (TIBC), free iron and hepcidin as iron overload indices, and even the prescription of iron-chelating agents in critically ill cases in ICU. We suggest that the safety and efficacy of ironchelating agents such as deferasirox at a right dose in critically circumstances such as sepsis be delineated. Importantly perhaps, among iron-chelators, deferasirox can be considered as a more suitable choice compared to other iron chelator agents e.g. deferoxamine and deferiprone in these patients owing to its antioxidant and anti-inflammatory properties (9). Besides, further studies are needed to assess iron metabolism flaw in conjunction with the evaluation of potential mechanisms of iron surplus in critical cases in ICU.

\section{Conflict of Interest}

Authors declared no conflict of interest.

\section{References}

1. Tacke F, Nuraldeen $\mathrm{R}$, Koch $\mathrm{A}$, et al. Iron parameters determine the prognosis of critically ill patients. Crit Care Med. 2016;44(6):1049-58. [DOI:10.1097/CCM.0000000000001607] [PMID]

2. Libert N, Harrois A, Duranteau J. Impact of alteration of iron homeostasis in ICU patients. Crit Care Med. 2016;44(6):1231-2. [DOI:10.1097/CCM.0000000000001788] [PMID]

3. Mireles-Cabodevila E, Meena N. Plasma ferritin level in the intensive care unit. Am J Respir Crit Care Med. 2011;183:A4730. 
4. Simon D, Nicol JMB, Sabino da Silva S, et al. Serum ferritin correlates with Glasgow coma scale scores and fatal outcome after severe traumatic brain injury. Brain Inj. 2015;29(5):612-7. [DOI:10.3109/02699052.2014.995228] [PMID]

5. Abilés J, de la Cruz AP, Castaño J, et al. Oxidative stress is increased in critically ill patients according to antioxidant vitamins intake, independent of severity: a cohort study. Crit Care. 2006;10(5):R146. [DOI:10.1186/cc5068] [PMID] [PMCID]

6. Bermejo-Martin JF, Martín-Loeches I, Bosinger S. Inflammation and infection in critical care medicine. Mediat Inflamm. 2014;2014. [DOI:10.1155/2014/456256] [PMID] [PMCID]
7. Wessling-Resnick M. Iron homeostasis and the inflammatory response. Ann Rev Nutr. 2010;30:105-22.

[DOI:10.1146/annurev.nutr.012809.104804] [PMID] [PMCID]

8. Lapointe M. Iron supplementation in the intensive care unit: when, how much, and by what route? Crit Care. 2004;8(2):S37. [DOI:10.1186/cc2825]

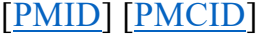

9. Meunier M, Ancelet S, Lefebvre C, et al. Reactive oxygen species levels control NF- $\kappa \mathrm{B}$ activation by low dose deferasirox in erythroid progenitors of low risk myelodysplastic syndromes. Oncotarget. 2017;8(62):105510.

[DOI:10.18632/oncotarget.22299] [PMCID]

How to Cite This Article:

Darvishi-Khezri H. Using Iron-Chelating Agents in Critically Ill Patients with Iron Overload. Fact or Fiction?. J Adv Med Biomed Res. 2021; 29 (133) :123-124

Download citation:

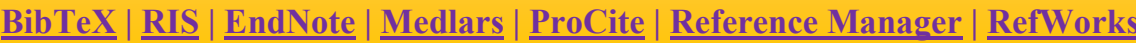

\section{Send citation to:}

(3) Mendeley 2 Zotero RefWorks RefWorks 